\title{
KUALITAS PELAYANAN DAN KEPUASAN MASYARAKAT PADA KINERJA PEGAWAI MENGGUNAKAN METODE ANALYSIS GAP DI KANTOR KECAMATAN SIMOKERTO SURABAYA
}

\author{
Enny Istanti \\ Fakultas Ekonomi dan Bisnis Universitas Bhayangkara Surabaya \\ Email : ennyistanti@gmail.com
}

\begin{abstract}
Globalization presents a number of challenges related to human resource management. Every organization is required to have quality Human Resources and have high competitiveness so that it can become an energy for the organization to compete with its competitors in the midst of increasingly dynamic changes. The purpose of this study was to determine the Quality of Service and Community Satisfaction on the Performance of Simokerto Sub-District Surabaya Office Employees by using GAP Analysis and Strategies of what employees did in carrying out services in Simokerto Sub-District Surabaya Office. The method used is a qualitative method with GAP analysis. The study population was conducted on all visitors from January 2019 to May 2019. The sampling procedure was based on accidental sampling technique. The sample of this study was $5 \times 10=50$ respondents. The results of the GAP analysis showed that there was a negative GAP of -0.272. Service Quality Indicators are expected to add air conditioners or improve existing air conditioners, wear uniforms and neat, perform services in accordance with predetermined SOPs, timeliness of services and maintain the confidentiality of visitor documents.
\end{abstract}

Keywords: Service Quality, Satisfaction, Performance, GAP Analysis.

\section{PENDAHULUAN}

Globalisasi memberikan sejumlah tantangan terkait dengan manajemen sumber daya manusia (SDM). Setiap organisasi dituntut untuk memiliki Sumber Daya Manusia yang berkualitas dan memiliki daya saing yang tinggi sehingga mampu menjadi energi bagi organisasi untuk bersaing dengan kompetitornya di tengah arus perubahan yang semakin dinamis. Tuntutan Sumber Daya Manusia yang berkualitas dan berdaya saing bukan hanya merupakan tututan organisasi dan kompetitornya, namun juga tuntutan pelanggan organisasi itu sendiri, terutama pelanggan eksternalnya. Saat ini pelanggan eksternal organisasi diharapkan pada banyaknya alternatif untuk mengambil keputusan sehingga ia memiliki banyak pilihan dalam menentukan produk dan jasa organisasi mana yang ia konsumsi.

Sumber daya manusia merupakan modal dasar pembangunan nasional, oleh karena itu, maka kualitas sumber daya manusia senantiasa sangat berperan besar dalam kesuksesan organisasi. Banyak organisasi dapat memberikan keunggulan bersaing mereka membuat sasaran, strategi, inovasi, dalam mencapai tujuan organisasi, oleh karena itu sumber daya manusia salah satu unsur vital bagi suatu organisasi.

Tinggi rendahnya Sumber Daya Manusia dilihat dari kinerja aparat pemerintah dan kualitas pelayanan dapat diukur sejauh mana aktifitas dan efisiensi dalam memberikan pelayanan kepada masyarakat. Faktor-faktor yang diperhitungkan gairah kerja aparat pemerintah adalah kualitas kemampuan dan kinerja yang dimiliki seorang aparatur dalam melayani masyarakat. Jadi kemampuan dan kinerja merupakan nilai-nilai yang harus diaplikasikan kepada seluruh aparat agar mereka menyadari bahwa mereka adalah pelayanan masyarakat yang berkewajiban dan bertanggung jawab penuh dalam rangka mengembang tugas-tugas yang diberikan oleh sebuah instansi pemerintahan.

Sebagaimana dipahami bahwa ensesi pemerintahan adalah pelayanan kepada masyarakat oleh karena itu pemerintah tidak diadakan untuk diri sendiri tetapi untuk melayani masyarakat serta menciptakan kondisi yang memungkinkan setiap anggota masyarakat mengembangkan kemampuan dan kreativitasnya demi mencapai tujuan bersama. Pelayanan publik merupakan segala kegiatan dalam rangka pemenuhan 
kebutuhan dasar sesuai dengan hak-hak dasar setiap warga Negara atau penduduk atas suatu barang, jasa dan pelayanan administrasi yang disediakan oleh penyelenggara pelayanan yang terkait dengan kepentingan publik. Contoh pelayanan publik dalam bentuk pelayanan administrasi yaitu pembuatan KTP (Kartu Tanda Penduduk) dan KK (Kartu Keluarga), Pelayanan dalam bentuk jasa misalnya Kantor Kecamatan.Tjiptono dalam Danang, (2012) mengatakan bahwa kualitas atau mutu dalam industri jasa pelayanan adalah suatu penyajian produk atau jasa sesuai ukuran yang berlaku di tempat produk tersebut diadakan dan penyampaiannya setidaknya sama dengan yang diingkan dan diharapkan oleh konsumen.

Pelayanan dan kepuasan masyarakat merupakan dua hal yang tidak dapat dipisahkan, karena dengan adanya kepuasan maka pihak terkait dpat saling mengkoreksi sampai dimana pelayanan yang diberikan apakah bertambah baik ataupun sebaliknya. Hal tersebut sangat dipengaruhi oleh setiap aparat petugas dalam memberikan pelayanan, dengan kata lain pelayanan yang dapat memuaskan adalah pelayanan yang dilakukan berdasarkan ketentuan yang berlaku dan dapat memahami apa yang diminta masyarakat untuk pelayanan itu sendiri.

Kepuasan (Satisfaction) adalah perasaan senang atau kecewa seseorang yang muncul setelah membandingkan kinerja (hasil) produk yang dipikirkan terhadap kinerja (atau hasil) yang diharapkan. Jika kinerja berada di bawah harapan maka pelanggan tidak puas. Jika kinerja memenuhi harapan maka pelanggan puas. Jika kinerja melebihi harapan maka pelanggan amat puas atau senang.(Kotler, 2006) Jadi, kepuasan merupakan fungsi dari persepsi atau kesan atas kinerja dan harapan.

Kinerja adalah tingkat terhadapnya para pegawai mencapai persyaratan pekerjaan secara efisien dan efektif .(Simamora, 2006) kinerja pegawai merupakan prestasi kerja, yakni perbandingan antara hasil kerja yang dapat dilihat secara nyata dengan standar kerja yang telah ditetapkan organisasi. Kemudian definisi kinerja yaitu suatu hasil yang dicapai oleh pegawai dalam pekerjaanya menurut kriteria tertentu yang berlaku untuk suatu pekerjaan.(Robbins, 2008)

Atas dasar latar belakang diatas maka perumusan masalahnya 1. Bagaimana Kualitas Pelayanan dan Kepuasan Masyarakat pada Kinerja Pegawai Kantor Kecamatan Simokerto Surabaya dengan menggunakan Analisis GAP ? 2. Strategi apa yang dilakukan pegawai dalam melaksanakan pelayanan di Kantor Kecamatan Simokerto Surabaya?

\section{LANDASAN TEORI Kualitas Pelayanan}

Dalam presfektif TQM (Total Quality Management) kualitas dipandang secara luas, yaitu tidak hanya aspek hasil yang ditekankan, tetapi juga meliputi proses, lingkungan dan manusia. Hal ini definisi yang dikutip Tjiptono dalam Antoni (2017:14) bahwa kualitas merupakan suatu kondisi dinamis yang berhubungan dengan produk, jasa, manusia, proses dan lingkungan yang memenuhi atau melebihi harapan. Sebaliknya, definisi kualitas yang bervariasi dari yang kontroversional hingga kepada yang lebih strategik. Ciri-ciri pelayanan yang baik menurut Kasmir, (2005) dirumuskan sebagai berikut :

1) Bertanggung jawab kepada setiap pelanggan/pengunjung sejak awal hingga selesai.

2) Mampu melayani secara cepat dan tepat.

3) Mampu berkomunikasi.

4) Mampu memberikan jaminan kerahasiaan setiap transaksi.

5) Memiliki pengetahuan dan kemampuan yang baik.

6) Berusaha memahami kebutuhan pelanggan/pengunjung.

Mampu memberikan kepercayaan kepada pelanggan/pengunjung

\section{Kepuasan masyarakat}

Kepuasan masyarakat terhadap organisasi publik sangat penting karena adanya hubungan kepercayaan masyarakat. Kepuasan pelanggan adalah perasaan senang atau kecewa yang didapatkan seseorang dari membandingkan antara kinerja atau hasil produk yang dipersepsikan dan ekspektasinya.(Tjiptono, 2015) Kepercayaan masyarakat akan semakin tinggi apabila masyarakat mendapatkan pelayanan yang baik dan merasa terpuaskan akan pelayanan tersebut. 


\begin{abstract}
Kinerja
Menurut Simamora (2003:45) kinerja adalah ukuran keberhasilan organisasi dalam mencapai misinya. Pengertian tersebut maka dapat dikatakan bahwa kinerja adalah kombinasi dari kemampuan, usaha dan kesempatan yang dapat dinilai dari hasil kerjanya yang diperoleh selama periode waktu tertentudan meliputi elemen-elemen seperti kuantitas dari hasil, kualitas dari hasil, kehadiran dan kemampuan bekerja sama. Kinerja adalah melakukan sesuatu kegiatan dan menyempurnakan sesuai dengan tanggung jawabnya dengan hasil seperti yang diharapkan.
\end{abstract}

\title{
Analisis GAP
}

Analisis Kualitas Pelayanan atau Service Quality adalah suatu metode deskriptif guna menggambarkan tingkat kepuasan pelanggan. Dalam buku Tjiptono dan Chandra dalam Hasibuan (2019:13), lima kesenjangan-kesenjangan yang tersebut antara lain :Gap 1 (Knowledge Gap), Gap 2 (Standards Gap), Gap 3 (Delivery Gap), Gap 4 (Communication Gap) dan Gap 5 (Service Gap)

\section{Pengertian Kecamatan}

Kecamatan adalah wilayah kerja camat sebagai perangkat daerah kabupaten/ kota. Status kecamatan menurut Undang-Undang No.32/2004 status kecamatan bukan lagi sebagai wilayah administrasi tapi sebagai wilayah kerja camat sebagai perangkat daerah kabupaten/ kota. Kecamatan merupakan line office dari pemerintah daerah yang berhadapan langsung dengan masyarakat dan mempunyai tugas membina desa/ kelurahan. Kecamatan merupakan perangkat daerah kabupaten atau kota yang mempunyai wilayah kerja tertentu yang dipimpin oleh seorang camat. Wilayah kecamatan terdiri atas beberapa desa atau kelurahan.

\section{METODOLOGI PENELITIAN}

Penelitian ini menggunakan metode kualitatif yaitu mengungkapkan masalah atau keadaan sebagaimana mestinya, sehingga dapat diketahui kelemahannya yang ada dalam metode pelayanan guna ditarik kesimpulan dan saran-saran. Penelitian ini dilakukan pada semua pengunjung yang membutuhkan pelayanan di Kantor Kecamatan Simokerto Surabaya dilakukan selama 5 bulan, yaitu dari bulan Januari 2019 sampai Mei 2019. Prosedur pengambilan sampel berdasarkan teknik sampling aksidental (accidental sampling). Sampel penelitian ini adalah 5x10 $=50$ responden yang membutuhkan pelayanan di Kantor Kecamatan Simokerto Surabaya dari bulan Januari 2019 sampai Mei 2019. Penelitian dengan asumsi analisis GAP yang mengacu pada hasil pelayanan yang sesuai dengan harapan masyarakat Kecamatan Simokerto Surabaya. Unit analisis merupakan komponen ketiga secara fundamental yang berkaitan dengan masalah penentuan kasus dalam penelitian yang bersangkutan. Oleh karena itu, unit analisis yang terkait dengan pelayanan dan kepuasan dalam kinerja pegawai yaitu :Data dari Kantor Kecamatan Simokerto, Kuesioner pada bulan maret 2019 dan Analisis GAP.

\section{ANALISIS DATA DAN PEMBAHASAN Analisis GAP}

Respon pengunjung terhadap kualitas pelayanan di Kantor Kecamatan Simokerto mencakup dimensi bukti fisik, keandalan, daya tanggap, jaminan dan kepedulian. Dengan skala jawaban 1-5, yakni Tidak Diharapkan (TD) bernilai 1, Agak Diharapkan (AD) bernilai 2, Diharapkan (D) bernilai 3, Sangat Diharapkan ( SD) bernilai 4 serta Sangat Diharapkan Sekali (SDS) bernilai 5. Hasil jawaban responden terkait dengan harapan (X) dan kenyataan (Y) atas kualitas pelayanan di Kantor Kecamatan Simokerto Surabaya dapat dijelaskan sebagai berikut : 
Tabel 1

GAP antara Harapan dan Kenyataan atas Kualitas Pelayanan

\begin{tabular}{|c|c|c|c|c|}
\hline $\mathbf{A}$ & Bukti Fisik & $\begin{array}{c}\text { Harapan } \\
(\mathrm{X})\end{array}$ & $\begin{array}{l}\text { Kenyataan } \\
(\mathrm{Y})\end{array}$ & $\sum_{\mathrm{GAP}}$ \\
\hline 1 & Lokasi dan Lahan kecamatan sudah memenuhi syarat & 3,88 & 3,36 & $-0,52$ \\
\hline 2 & Lokasi parkir sudah memenuhi syarat & 3,68 & 3,32 & $-0,36$ \\
\hline 3 & Ruang pelayanan yang standart & 3,74 & 3,32 & $-0,42$ \\
\hline 4 & Ruang tata baik & 3,88 & 3,34 & $-0,54$ \\
\hline 5 & Ada papan informasi, TV, Majalah & 3,88 & 3,2 & $-0,68$ \\
\hline 6 & Semua ruangan terasa nyaman dan berAC & 3,88 & 3,14 & $-0,74$ \\
\hline 7 & Terdapat Fasilitas toilet dikantor & 3,72 & 3,38 & $-0,34$ \\
\hline 8 & Terdapat area smoking & 3,74 & 3,16 & $-0,58$ \\
\hline 9 & Pelayanan & 3,94 & 3,52 & $-0,42$ \\
\hline 10 & Fasilitas Penunjang pelayanan seperti komputer, printer dll & 3,64 & 3,64 & 0 \\
\hline 11 & Ruang tunggu dengan Tempat duduk yang cukup & 3,28 & 3,52 & 0,24 \\
\hline$\sum$ & Rata-rata Total & 3,75 & 3,35 & $-0,40$ \\
\hline B & Keanadalan & & & \\
\hline 1 & Pegawai Front Office berkompeten dalam layanan & 3,88 & 3,6 & $-0,28$ \\
\hline 2 & Seluruh pegawai bekerja dengan handal & 3,78 & 3,54 & $-0,24$ \\
\hline 3 & mengarahkan dalam pelayanan & 3,92 & 3,66 & $-0,26$ \\
\hline 4 & Pegawai mudah memberi informasi & 3,84 & 3,48 & $-0,36$ \\
\hline 5 & Pegawai mencukupi dalam pelayanan & 3,68 & 3,38 & $-0,3$ \\
\hline 6 & Pelayanan sesuai kedatangan antrean & 3,64 & 3,4 & $-0,24$ \\
\hline 7 & Pegawai berseragam dan rapi & 3,82 & 3,3 & $-0,52$ \\
\hline$\sum$ & Rata-rata Total & 3,79 & 3,48 & $-0,31$ \\
\hline C & Daya Tanggap & & & \\
\hline 1 & Pegawai dapat memberi informasi yang mudah dipahami & 3,72 & 3,62 & $-0,1$ \\
\hline 2 & Pegawai bertanggung jawab & 3,76 & 3,38 & $-0,38$ \\
\hline 3 & Pegawai bersahabat & 3,88 & 3,3 & $-0,58$ \\
\hline 4 & $\begin{array}{l}\text { Pegawai memberi kesempatan bertanya dan mudah } \\
\text { memberikan jawaban }\end{array}$ & 3,96 & 3,32 & $-0,64$ \\
\hline 5 & $\begin{array}{l}\text { Pegawai memberikan alur petunjuk layanan sesuai SOP } \\
\text { (Prosedur) }\end{array}$ & 4,16 & 3,16 & -1 \\
\hline 6 & Pegawai ramah dan sabar & 3,86 & 3,5 & $-0,36$ \\
\hline 7 & Pegawai bekerja dengan cekatan & 3,86 & 4,48 & 0,62 \\
\hline$\sum$ & Rata-rata Total & 3,89 & 3,54 & $-0,35$ \\
\hline D & Jaminan & & & \\
\hline 1 & Pegawai sopan dalam pemanggilan pengunjung & 4 & 3,72 & $-0,28$ \\
\hline 2 & Ketepatan Pelayanan (Waktu yang tepat) & 3,9 & 3,5 & $-0,4$ \\
\hline 3 & Pegawai tidak bertele-tele & 3,8 & 3,54 & $-0,26$ \\
\hline 4 & Tidak ada pungutan liar & 3,8 & 3,38 & $-0,42$ \\
\hline 5 & Kejujuran Pegawai & 3,9 & 3,44 & $-0,46$ \\
\hline 6 & Kecepatan proses pelayanan & 3,98 & 3,4 & $-0,58$ \\
\hline 7 & Ketepatan waktu Pelayanan & 3,86 & 3,38 & $-0,48$ \\
\hline 8 & $\begin{array}{l}\text { Tidak berbuat kesalahan dalam tanggung jawab pelayanan } \\
\text { administrasi dan KTP }\end{array}$ & 4,02 & 3,58 & $-0,44$ \\
\hline
\end{tabular}




\begin{tabular}{rlccc}
$\sum$ & \multicolumn{1}{c}{ Rata-rata Total } & 3,91 & 3,49 & $-0,42$ \\
$\mathbf{E}$ & Kepedulian & & & \\
1 & Pegawai berkomunikasi dengan sopan & 3,92 & 3,54 & $-0,38$ \\
2 & Pegawai membantu dengan ikhlas dan sabar & 3,84 & 3,44 & $-0,4$ \\
3 & Kepedulian layanan & 4,06 & 3,56 & $-0,5$ \\
4 & Memahami kebutuhan administrasi & 3,98 & 3,52 & $-0,46$ \\
5 & Adanya sarana pendampingan dari pegawai & 3,82 & 3,44 & $-0,38$ \\
6 & Menjaga rahasia dokumen pengunjung & 4,06 & 3,4 & $-0,66$ \\
$\sum$ & Rata-rata Total & 3,95 & 3,48 & $-0,46$
\end{tabular}

Berdasarkan hasil jawaban responden terkait dengan harapan dan kenytaan atas kualitas pelayanan di Kantor Kecamatan Simikerto diuraikan dalam GAP antara harapan dan kenyataan kualitas pelayanan disajikan dalam tabel 2

Tabel 2

GAP antara Hapan dan Kenyataan Kualitas Pelayanan

\begin{tabular}{|l|c|c|c|}
\hline Dimensi & $\Sigma X$ & $\Sigma \mathrm{Y}$ & GAP \\
\hline Bukti Fisik & 3,75 & 3,35 & $-0,4$ \\
\hline Keandalan & 3,79 & 3,48 & $-0,31$ \\
\hline Daya Tanggap & 3,89 & 3,54 & $-0,35$ \\
\hline Jaminan & 3,91 & 3,49 & $-0,42$ \\
\hline Kepedulian & 3,95 & 4,07 & 0,12 \\
\hline
\end{tabular}

Dengan melakukan perhitungan nilai kesenjangan pada setiap dimensi kualitas pelayanan jasa, maka dapat diketahui tingkat kesesuaian antara harapan dan kenyataan pada setiap dimensi. Dari hasil perhitungan, nilai GAP tertinggi adalah dimensi empaty dengan nilai GAP sebesar .0,12 dan nilai GAP terendah pada dimensi assurance dengan nilai GAP $-0,12$

\section{Kesenjangan GAP antara Tingkat Kepentingan (Harapan) dan Tingkat Kinerja (Kenyataan)}

Kualitas Pelayanan pada setiap kriteria pelayanan (faktor-faktor yang mempengaruhi kualitas pelayanan terhadap pengguna jasa) digambarkan oleh nilai GAP anatara penilaian harapan dan kenyataan. Nilai GAP negatif menunjukkan kualitas pelayanan suatu kriteria kurang baik sehingga perlu ditingkatkan. Idealnya adalah nilai gap anatara kenyataan dan harapan adalah nol, dalam kondisi tersebut tingkat kepentingan (harapan) terhadap suatu kriteria pelayanan adalah sama dengan kinerja (pelayanan yang diterima) terhadap kriteria yang diterima pula. Bila nilai positif, hal ini menunjukkan bahwa tingkat kinerja terhadap suatu kualitas pelayanan melebihi tingkat kepentingan terhadap kriteria yang sama. Semakin besar nilai negatif suatu gap pada suatu kriteria pelayanan, maka semakin besar pula prioritas peningkatan kualitas pelayanan dari kriteria tersebut.

Dimensi Pelayanan Bukti Fisik merupakan tanggapan pengunjung terhadap fasilitas fisik yang ada di Kantor Kecamatan Simokerto seperti peralatan, perlengkapan dan fasilitas IT. Secara rata-rata gap yang terjadi antara harapan dan kenyataan sebesar $-0,4$ dari dimensi bukti fisik yang memiliki gap paling kecil dengan tingkat kepuasan terbesar adalah Ruang tunggu dengan Tempat duduk yang cukup sedangkan item yang memiliki gap paling besar dengan tingkat kepuasan terkecil adalah Semua ruangan terasa nyaman dan berAC, kualitas pelayanan pada dimensi ini belum sesuai dengan harapan oleh karena itu diharapakan menambah AC dan Ac yang ada diperbaiki supaya dingin

Dimensi Pelayanan Keandalan merupakan tanggapan pengunjung terhadap keandalan kinerja Kantor Kecamatan Simokerto dalam hal akurasi dan pelayanan yang sesuai janji sehingga mampu 
memuaskan para pengunjung. Secara rata-rata gap yang terjadi adalah $-0,31$ pelayanan yang memiliki gap terkecil adalah Pegawai mencukupi dalam pelayanan sedangkan gap yang terbesar adalah Pegawai berseragam dan rapi dari dimensi keandalan yang diberikan belum sesuai dengan harapan untuk itu pegawai perlu meningkatkan keseragaman dan kerapihan dalam berseragam agar keandalan dapat memenuhi harapan pengunjung.

Dimensi Daya Tanggap merupakan tanggapan pengunjung terhadap kesediaan para pegawai memberikan pelayanan secara tanggap. Rata-rata gap yang terjadi sebsesar $-0,35$ daya tanggap yang memiliki gap terkecil adalah Pegawai dapat memberi informasi yang mudah dipahami sedangkan daya tanggap yang memiliki gap terbesar adalah Pegawai memberikan alur petunjuk layanan sesuai SOP (Prosedur) Hal ini menunjukkan bahwa pegawai diharapkan mampu meningkatkan kinerjanya sesuai dengan SOP yang berlaku.

Dimensi Jaminan merupakan tanggapan terhadap kesediaan pegawai kantor Kecamatan dalam meberikan pelayanan terhadap pengunjung yang membutuhkan. Rata-rata gap adalah -0,42 Pada dimensi Jaminan gap yang terkecil adalah Pegawai tidak bertele-tele dan gap yang terbesar adalah Kecepatan proses pelayanan. Dalam hal ini pegawai diharapkan mampu meningkatkan pelayanan dan mengefektifkan waktu

Dimensi Kepedulian merupakan tanggapan pengunjung terhadap perhatian secara personal yang diberikan pegawai yang ada. Rata-rata gap yang terjadi 0,12. Pada dimensi kepedulian gap yang terbesar adalah Pegawai berkomunikasi dengan sopan dan gap yang terkecil adalah Menjaga rahasia dokumen pengunjung. Dalam hal ini diharapkan pegawai mampu amanah dan menjaga kerahasiaan dokumen.

\section{Pembahasan}

Dari permasalahan yang timbul perlu adanya pembahasan untuk perbaikan kualitas pelayanan dan kepuasan masyarakat pada kinerja pegawai di kantor Kecamatan Simokerto Surabaya. Dalam hal ini dapat dirangkum sebagai berikut :

1) Pada dimensi pelayanan bukti fisik diharapkan kantor Kecamatan Simokerto menambah lagi AC atau memperbaiki AC yang ada yang mana kondisinya tidak dingin.

2) Untuk pegawai kantor Kecamatan diharapkan memakai seragam yang telah ditentukan dan rapi

3) Pegawai diharapkan lebih mengoptimalkan pelayanan sesuai dengan SOP yang telah ditentukan

4) Pegawai diharapkan mampu memperbaiki waktu pelayanan agar sesuai dengan yang diharapkan pengunjung

5) Pegawai diharapkan mampu menjaga kerahasiaan dokumen pengunjung.

\section{KESIMPULANt}

Berdasarkan hasil penelitian dapat diambil kesimpulan sebagai berikut :

1) Hasil dari analisis GAP menunjukkan bahwa rata-rata harapan pelayanan yang diberikan oleh pegawai kantor Kecamatan Simikerto Surabaya mencapai 3,858 dan rata-rata kenyataan pelayanan yang diberikan pegawai Kecamatan Simokerto Surabaya mencapai 3,586 sehingga terdapat GAP negatif sebesar -0,272. Ini berarti kenyataan kualitas pelayanan yang diberikan belum sesuai dengan harapan yang diiningkan oleh pengunjung Kantor Kecamatan Simokerto Surabaya.

2) Ada 5 indikator Kualitas Pelayanan yang diharapkan pengunjung pada pegawai kantor Kecamatan Simokerto Surabaya yaitu menambah Ac atau memperbaiki AC yang ada, pagawai memakai seragam dan rapi, melakukan pelayanan sesuai dengan SOP yang telah ditentukan, ketepatan waktu pelayanan dan manjaga kerahasiaan dokumen pengunjung.

\section{SARAN}

Berdasarkan kesimpulan diatas maka saran yang diberikan adalah sebagai berikut :

1) Penelitian ini memiliki keterbatasan diantaranya penelitian hanya dlakukan pada Kualitas Pelayanan pada Kantor Kecamatan Simokerto. Sehingga perlu dilakukan penelitian lebih lanjut terhadap perkantoran penyedia jasa lainnya dan mengenai perilaku pengunjung terhadap keinginan pemenuhan kepuasan dalam pelayanan. 
2) Untuk strategi perbaikannya para pegawai kantor kecamatan Simokerto Surabaya diharapkan lebih efektif dan efisien dalam pelayanan terhadap masyarakat yang melakukan kunjungan ke kantor kecamatan agar pengunjung merasa puas

3) Perlu adanya penelitian lebih mendalam mengenai kepuasan pengunjung yang dikaitkan dengan sarana dan prasarana serta pelayanan jasa.

\section{DAFTAR PUSTAKA}

Alfi Syahri Lubis1), N. R. A. (2017) 'PENGARUH KUALITAS PELAYANAN (SERVICE QUALITY) TERHADAP KEPUASAN PELANGGAN PT. SUCOFINDO BATAM', Journal of Business Administration, 1(2), pp. 232-243. Available at: https://jurnal.polibatam.ac.id/index.php/ JABA/article/download/619/431/.

Danang, S. (2012). Manajemen Sumber Daya Manusia. Jakarta: PT Buku Seru.

Florensia Kurnia Puung1), Achmad Fudholi2), B. S. D. (2014) 'ANALISIS PENGARUH KUALITAS PELAYANAN PADA KEPUASAN DAN LOYALITAS PELANGGAN DI SALON DAN SPA', Jurnal Manajemen dan Pelayanan Farmasi, 4(2), pp. 105-110. Available at: https://jurnal.ugm.ac.id/jmpf/article/download/29440/17584.

Heni Rohaeni, N. M. (2018) 'Kualitas Pelayanan Terhadap Kepuasan Pelanggan', Jurnal Ecodemica, 2(2), pp. 312-318. doi: https://doi.org/10.31311/jeco.v2i2.4503.

Herri Affandi 1, Muhammad Zaki2, Azmeri2, 3 (2017) 'PENGARUH KUALITAS PELAYANAN TERHADAP KEPUASAN PELANGGAN PADA PERUSAHAAN DAERAH AIR MINUM (PDAM) TIRTA MON PASE KABUPATEN ACEH UTARA', Jurnal Teknik Sipil Universitas Syiah Kuala, 6(3), pp. 297-308. Available at: http://www.jurnal.unsyiah.ac.id/JTS/article/download/9845/7805.

Istiatin, E. N. \& (2015) 'PENGARUH KUALITAS PELAYANAN TERHADAP KEPUASAN KONSUMEN PADA DEALER PT. RAMAYANA MOTOR SUKOHARJO', Jurnal Paradigma, 13(1), pp. 1-12. Available at: https://media.neliti.com/media/publications/115736-ID-pengaruhkualitas-pelayanan-terhadap-kep.pdf.

Kasmir. (2005). Etika Customer Service. Jakarta: RajaGrafindo Persada.

Khoirista, A. (2015) 'PENGARUH KUALITAS PELAYANAN TERHADAP KEPUASAN PELANGGAN (Survey Pada Pelanggan Fedex Express Surabaya)', Jurnal Administrasi Bisnis $(J A B)$, 25(2), pp. $1-7 . \quad$ Available at: http://administrasibisnis.studentjournal.ub.ac.id/index.php/jab/article/view/1000/1182.

Kotler, P. (2006). Manajemen Pemasaran (Edisi Pert). Indonesia: PT. Indeks Kelompok Gramedia.

Panjaitan, J. E. (2016) 'PENGARUH KUALITAS PELAYANAN TERHADAP KEPUASAN PELANGGAN PADA JNE CABANG BANDUNGNo Title', DeReMa Jurnal Manajemen, 11(1), pp. 265-289. Available at: https://ojs.uph.edu/index.php/DJM/article/download/197/130.

Robbins, S. (2008). Perilaku Organisasi ( alih B. : Hadyana \& Pujaatmaja, eds.). Jakarta: Prenhallindo.

Simamora, H. (2006). Manajemen Sumberdaya Manusia. Yogyakarta: Sekolah Tinggi Ilmu Ekonomi YKPN. 
Sulistyawati, Ni Made Arie and Seminari, N. K. (2015) 'PENGARUH KUALITAS PELAYANAN TERHADAP KEPUASAN PELANGGAN RESTORAN INDUS UBUD GIANYAR', E-Jurnal Manajemen Unud, 4(8), pp. 2318-2332. Available at: https://media.neliti.com/media/publications/250437-pengaruh-kualitas-pelayanan-terhadap-kepffc2ebd9.pdf.

Tjiptono, F. (2015). Strategi Pemasaran. Yogyakarta: Andi. 